\title{
Modified H-shaped Microstrip Array Antennas for WiMAX Applications
}

\author{
M.Vinoth ${ }^{[1]}$, Mr.S.Bashyam ${ }^{[2]}$, \\ M.Tech Scholar, Department Of Ece ${ }^{[1]}$, \\ Assistant Professor, Department Ece ${ }^{[2]}$ \\ Srm University Kattankulathur, Chennai
}

\begin{abstract}
Modified H-shaped array antennas are proposed to achieve high gain and good impedance matching for WiMAXapplications. Here a $3 * 2$ H-shaped microstrip array antenna is designed. To reduce the return loss and for good impedance matching, the $50 \mathrm{ohm}$ impedance transformer is used. By using H-shaped slot antenna, an air bridge can be avoided in design as well as the complexity of design can be reduced .The 180 degree phase shifters are organised in $\mathrm{H}$-shaped antenna. It gives $7.77 \mathrm{~dB}$ gain and $11.97 \mathrm{~dB}$ directivity. The return loss of $16 \mathrm{~dB}$ and $24 \mathrm{~dB}$ can be achieved at $3.3 \mathrm{GHz}$ and $3.7 \mathrm{GHz}$ operating frequencies which are WiMAX frequencies.

Index Terms:Modified H-shaped antenna, WiMAX, $50 \mathrm{ohm}$ impedance transformer, 180 deg phase shifter.
\end{abstract}

\section{Introduction}

Microstrip antennas are attractive due to their light weight, conformability and low cost [1-5]. These antennas can be integrated with printed strip-line feed networks and active devices. This is a relatively new area of antenna engineering. The radiation properties of microstrip structures have been known since the mid 1950's. The application of this type of antennas started in early 1970's when conformal antennas were required for missiles.

Microstrip patch antennas have a very high antenna quality factor $(\mathrm{Q})$. It represents the losses associated with the antenna where a large $\mathrm{Q}$ leads to narrow bandwidth and low efficiency. $\mathrm{Q}$ can be reduced by increasing the thickness of the dielectric substrate. WiMAX stands for Worldwide Interoperability for Microwave Access [6-7]. It was introduced in 2001. IEEE802.16 is the standard of WiMAX [9]. It is an advancement of Wi-Fi technology [9]. And also it covers area larger than Wi-Fi. We can get nearly 1GB speed for fixed users by using current WiMAX technology.

The previous researchers have tried many structures. U slot microstrip array antenna was proposed for WiMAX base station. They have used quarter wave impedance transformer which didn't give desirable impedance matching [1].Y shaped slot and U slot were proposed symmetrically and asymmetrically in order to achieve WiMAX coverage. They were achieved $15 \mathrm{~dB}$ of return loss [2]. A reconfigurable microstrip patch array antenna which was achieved by integrating the conventional microstrip antenna with switches. Here patches were movable by helping of RF switch [3].

In pi-shaped slot antenna the substrate thickness was increased to broaden the bandwidths at desired operating frequencies [6]. One L-slit and one $\mathrm{H}$-slit were introduced in patch antenna. The antenna size had been reduced by $75 \%$ when compared to conventional antenna [7]. A double U slot microstrip antenna was used for mobile WiMAX application. But they were achieved nearly $-16 \mathrm{~dB}$ of return loss only. One of the drawbacks was complicated antenna structure [9].

The proposed $\mathrm{H}$-shaped microstrip array antenna is designed as $3 * 2$ array structure for WiMAX applications. 50ohm impedance transformer has been proposed to achieve the good impedance matching. An air bridge could also be avoided by using $\mathrm{H}$-shaped slot in patch antenna. The return loss of the antenna is $-16 \mathrm{~dB}$ and $-24 \mathrm{~dB}$ at 3.3 and $3.7 \mathrm{GHz} .40 \%$ of antenna efficiency has achieved over the design. As well as the result has shown that antenna gain and directivity are $8 \mathrm{~dB}$ and $11 \mathrm{~dB}$. The detailed analysis of antenna design and emblematic experimental results are also presented below.

\section{Antenna Design}

\section{DESIGN OF 3*2 H-SHAPED MICROSTRIP ARRAY ANTENNA}

The configuration of proposed antenna is shown in fig. 1(a).It consists of $(3 * 2)$ antenna array structure. In this figure each two patches are connected parallel. In each patch two H-shaped slots are designed. The distance between two parallel patches is $6.4 \mathrm{~mm}$. While placing another $2 * 1$ patch the distance between two patches is $23.4 \mathrm{~mm}$. In this design, the power is fed at bottom of the design. Then power is scattered over all the patches through strip lines. 


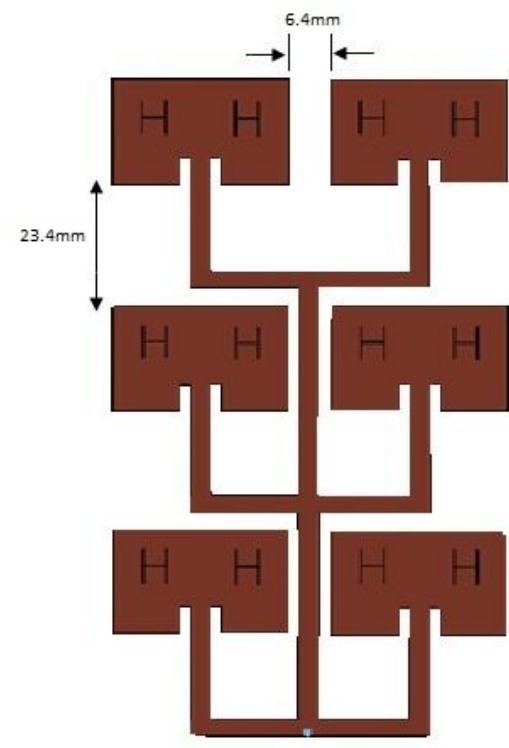

Fig. 1(a) $3 * 2$ H-shaped microstrip array antenna

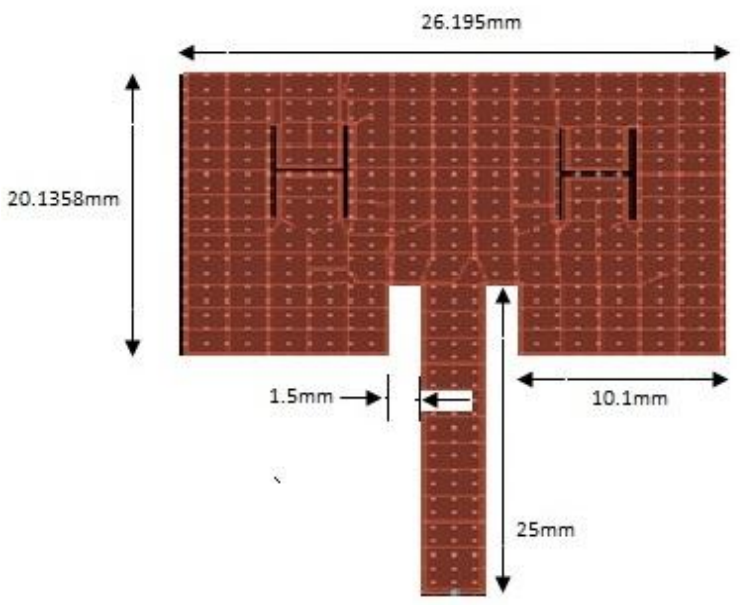

Fig. 1(b) Single H-slot microstrip antenna

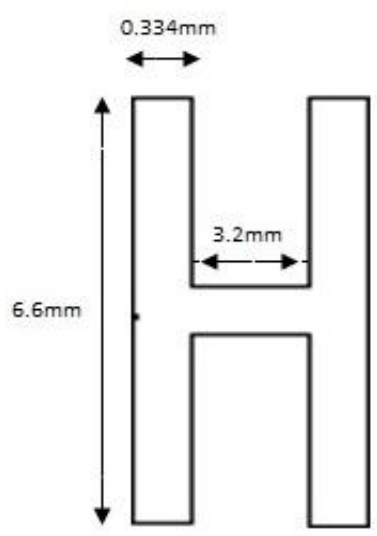

Fig. 2 H-Slot dimensions

Fig. 1(b) shows the Single patch antenna design. The dimensions for this design is $(26.195 \mathrm{~mm}(\mathrm{~L}) * 20.1358 \mathrm{~mm}$ (W)). There are number of feeding techniques are available. But, here inset fed technique is used to get the optimized result. Strip line dimensions are calculated by patch length and width. The dimension is $(11.8 \mathrm{~mm} * 3.1 \mathrm{~mm})$. Fig. 2 shows the H-slot dimensions which is $6.6 \mathrm{~mm}$ of length and $0.334 \mathrm{~mm}$ of width. The following parameters are used in proposed work. Which are,

- Software tool: ADS

- Substrate: FR4

- Dielectric constant, $\varepsilon_{\mathrm{r}}=4.2$

- Operating frequency: 3.3 and $3.8 \mathrm{GHz}$

- Input impedance: $50 \mathrm{Ohm}$

- Thickness of the substrate: $1.6 \mathrm{~mm}$

To calculate the patch dimensions some of the basic formulas are used here. They are,

To calculate the width of the patch,

$$
W=\frac{1}{2 f \sqrt{\varepsilon_{0} \mu_{0}}} \sqrt{\frac{2}{\varepsilon_{r}+1}}
$$

To calculate the effective dielectric constant,

$$
{ }^{\mathcal{E}} \text { reff }=\left(\frac{\varepsilon_{r}+1}{2}\right)+\left[\left(\frac{\varepsilon_{r}-1}{2}\right)\left[1+12 \frac{h}{W}\right]^{-0.5}\right]
$$

To calculate the patch length extension,

$$
\Delta L=0.412 h \frac{\left(\varepsilon_{r e f f}+0.3\right)\left(\frac{W}{h}+0.264\right)}{\left(\varepsilon_{r e f f}-0.258\right)\left(\frac{W}{h}+0.8\right)}
$$


To calculate the patch length,

To calculate the effective length,

$$
L=\left(\frac{1}{2 f \sqrt{\varepsilon_{r e f f} \sqrt{\varepsilon_{0} \mu_{0}}}}\right)-2 \Delta L
$$

$$
L_{e}=L+2 \Delta L
$$

The below values are calculated by using this formulas and tabulated as well.

\begin{tabular}{|c|c|}
\hline PARAMETERS & VALUES(in mm) \\
\hline Width, $\mathrm{W}$ & 26.195 \\
\hline Effective dielectric constant, $\boldsymbol{\varepsilon}_{\text {reff }}$ & 3.82 \\
\hline Effective length, $L_{\text {eff }}$ & 20.1358 \\
\hline Length extension, $\delta l$ & 0.7386 \\
\hline Length, L & 20.1358 \\
\hline
\end{tabular}

Table 1. Patch dimensions

\section{A. LAYOUT STRUCTURE AND ISOMETRIC VIEW}

\section{Results And Discussion}
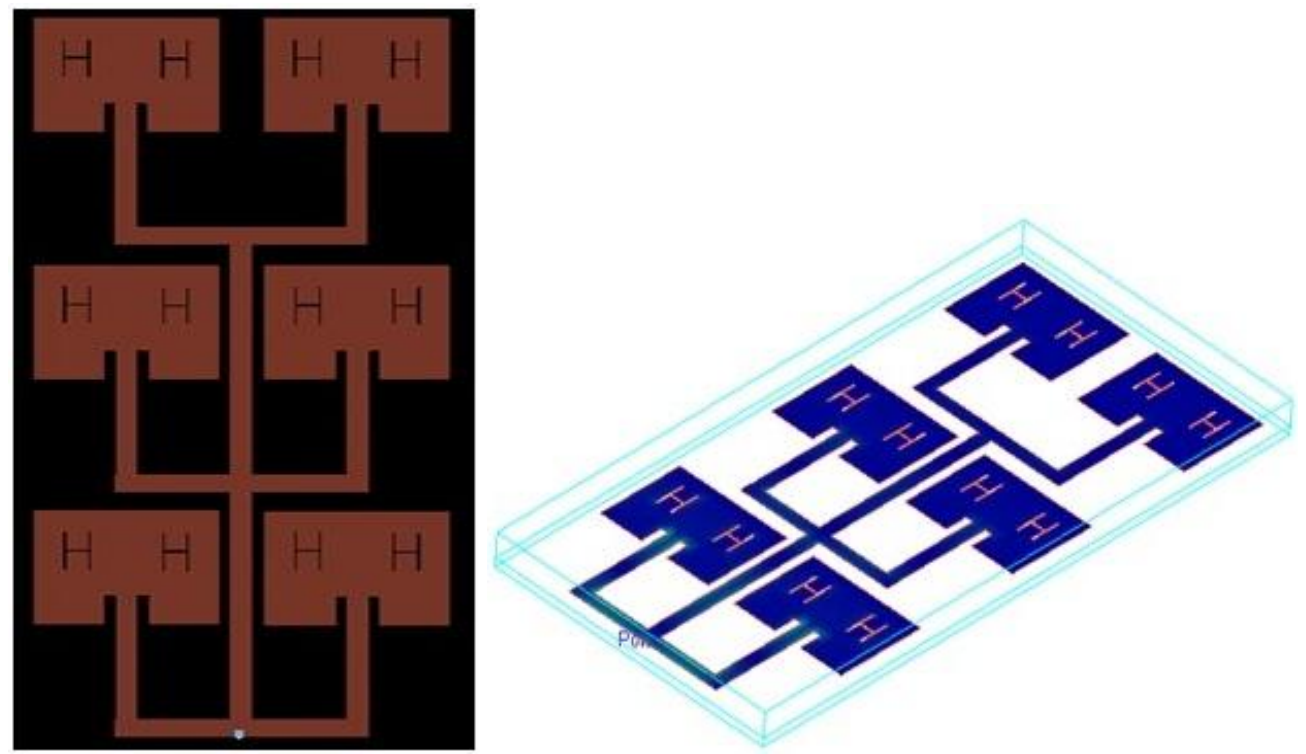

Fig. 4 Layout structure of $3 * 2 \mathrm{H}$-shaped microstrip array antenna

Fig. 5 Isometric view of the antenna

The layout structure of the antenna is shown in fig. 4. It is designed by using ADS simulation software. Here the port is connected at the bottom of the stripline. The fig. 5 shows that isometric view of the antenna. In this figure blue colour indicates power is radiated all over the patches.

\section{B. RETURN LOSS AND RADIATION PATTERN}

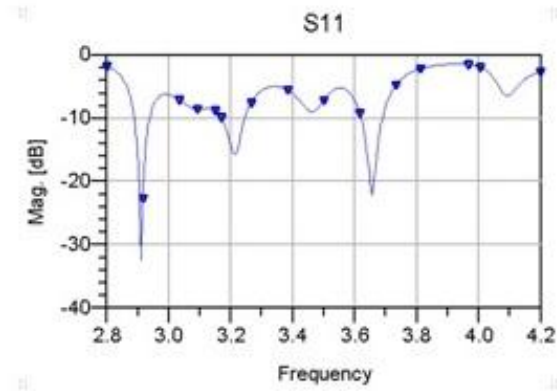

Fig. 6 Return loss

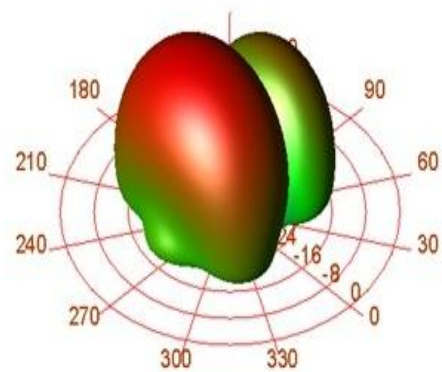

Fig. 7 Radiation pattern 
Simulated results of return loss of the proposed antenna is shown in Fig. 6. For the proposed antenna resonant frequencies are $3.25 \mathrm{GHz}, 3.5 \mathrm{GHz}, 3.7 \mathrm{GHz}$ and their corresponding return losses are $-16 \mathrm{~dB},-10 \mathrm{~dB} \&-24 \mathrm{~dB}$ respectively. Simulated $10 \mathrm{~dB}$ bandwidths are $195 \mathrm{MHz}, 145 \mathrm{MHz} \& 102 \mathrm{MHz}$ respectively.

The simulated 3-D radiation pattern of the proposed antenna is plotted which is given in Fig. 7 at three different resonating frequencies $(3.25 \mathrm{GHz}, 3.5 \mathrm{GHz}$ and $3.7 \mathrm{GHz})$. Radiation pattern is discovered to be almost omnidirectional type.

\section{GAIN, DIRECTIVITY AND EFFICIENCY}

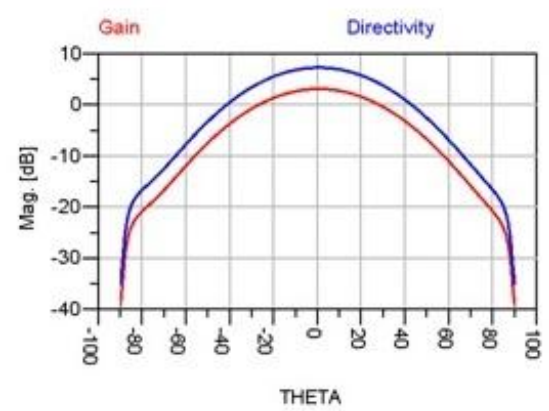

Fig. 8 Gain and Directivity

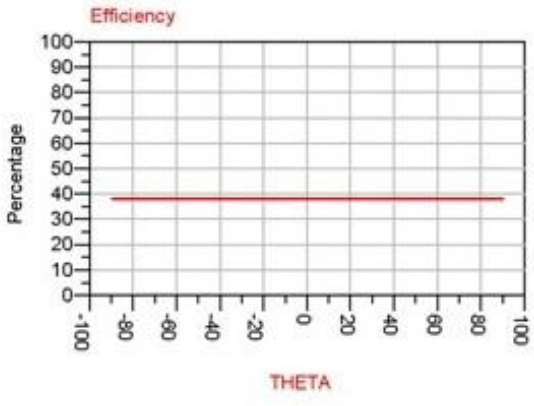

Fig. 9 Efficiency

The measured peak gain and efficiency variation of proposed $3 * 2 \mathrm{H}$-shaped microstrip array antenna are presented in Fig. 8 and Fig. 9, whereby an efficiency level of nearly $40 \%$ are demonstrated within the band of interest. Here, the peak gain of proposed $3 * 2 \mathrm{H}$-shaped microstrip array antenna at $3.7 \mathrm{GHz}$ is measured to be $9 \mathrm{dBi}$. The directivity of the antenna is measured to be $11 \mathrm{~dB}$ approximately.

\section{SMITH CHART}

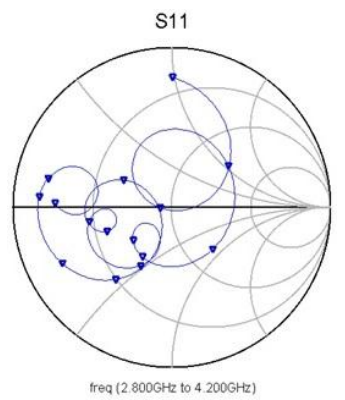

Fig. 10 Smith chart

The fig. 10 shows the smith chart of input impedance. S11 parameter values are perfectly matched with zero impedance line. It clearly explains that the input impedance is good matched. So the antenna design is very apt to get desired results.

\section{Conclusions}

This paper presented the simulation of the microstrip patch antenna with double H-slots. From two Hslots on the patch, the three bands are generated and the exact frequencies band for WiMAX would be achieved. The three frequency band $3.25 \mathrm{GHz}, 3.5 \mathrm{GHz}$ and $3.7 \mathrm{GHz}$ has been achieved as well as the bandwidth requirements for Wi-MAX standards $195 \mathrm{MHz}, 145 \mathrm{MHz}$ and $102 \mathrm{MHz}$ respectively. The re-turn loss for the triple band are $-16 \mathrm{~dB},-10 \mathrm{~dB}$ and $-24 \mathrm{~dB}$ respectively. The $\mathrm{H}$ - shaped microstrip array antenna is designed for increasing the bandwidth and return loss. The gain and efficiency of the antenna are 9dBi and 40\%. Therefore, the proposed antenna is well suitable for Wi-MAX applications.

\section{Acknowledgment}

The authors would like to thank the management of SRM University, Chennai for excellent encouragement during the tenure of work. 


\section{References}

[1] "Broadband High-gain Microstrip Array Antennas for WiMAX Base Station", horng-dean chen, chow-yen-desmondsim, jun-yiwu, andtsung-wen chiu, ieee transactions on antennas and propagation, vol. 60, no. 8, august 2012.

[2] "Slot Loaded Microstrip Antenna for GPS, Wi-Fi, and WiMAX Applications Survey", Pradutt K. Bharti1, H. S. Singh2, G. K. Pandey3, and M. K. Meshram4, International Journal of Microwaves Applications, Volume 2, No.2, March - April 2013.

[3] "A Reconfigurable Stacked Patch Microstrip Array Antenna (RSPMAA) for Long Term Evolution (LTE) and WiMAX Applications”, N. Ramli, M. T. Ali, A. L. Yusof, S. Muhamud @ Kayat, H. Alias, and M. A. Sulaiman.

[4] "A Compact Microstrip Patch Antenna with Triangular Snipped Slot for Wireless Applications", K.NagaMallik, Ch. Radhika, D.Ujwala, H.M.Ramesh, A. Gowtham Kumar, P.Karthik.

[5] "High Gain of C Shape Slotted Microstrip Patch Antenna for Wireless System",Anamika Singh, AadeshArya\&Sanjay Sharma.

[6] "Pi shape slot loaded patch antenna for Wi-MAX applications", Rajesh Khanna, Rakesh Kumar,Tripathi, Department of Electronics and Communication Engineering, ThaparUniversity,Patiala,Punjab,India.

[7] “A Compact Printed Antenna For Wimax, Wlan\& C Band Applications", BarunMazumdar, Assistant Professor, ECE Department, AIEMD, West Bengal, India.

[8] "Declined Rectangular Slotted Microstrip Patch Antenna for Wi-Max and S-Band Application", Sarthak Singh, Sakshi Singh, Jitesh Kumar, AnkitBajpai.

[9] "Compact double U-Slots Patch Antenna for Mobile WiMAXApplications",H. F. AbuTarboush, H. S. Al-Raweshidy and R. Nilavalan,Wireless Networks \& Communications Group (WNCG) School of Engineering \& Design, Brunel University, West London, UK.

[10] "Design \& Simulation of Double U-Slot Microstrip Patch Antenna for WiMAX Application", Md. SuaiburRahman, Md. MunjureMowla, Md. MahabubAlam ${ }^{3}$

[11] "Design and Study of Compact and Wideband Microstrip U-Slot Patch Antenna for Wi-Max Application", Sukhbir Kumar, Hitender Gupta.

[12] "Reconfigurable Beam Steer Antenna (RBSA) Design for WiMAX Application", M. Jusoh1, M. F. Jamlos2, Hasliza A. Rahim3, M. F. AbdMalek, M. R. Kamarudin, M. R. Hamid.

[13] C. A. Balanis, Antenna Theory Analysis and Design, Second Edition, New York, Wiley, 1997. 